\title{
Nonlinear seismic performance of a regular building using base isolation method
}

\author{
Vishal Yadav mallela ${ }^{1}$, Atulkumar manchalwar ${ }^{2}$ \\ ${ }^{1}$ Mtech Scholar, Gokaraju Rangaraju Institute of Engineering and Technology, Hyderabad, India \\ ${ }^{2}$ Associate Professor, Gokaraju Rangaraju Institute of Engineering and Technology, Hyderabad, India.
}

\begin{abstract}
Researches in past reviewed for base isolation analysis using response spectrum it is found that the design in ancient time are not sure and safe due to lake of technology and lesser software analysis availabilities. Some countries applied base isolation these days and the building response constructed with base isolation performed better at practical ground. The response of base isolated building is lesser in terms of amplitude and the cost of the building can also be optimized. Many researchers studied for this subject and they concluded that base isolation must be applied in critical seismic zones and the isolators must be used to save lives and properties. It is seen that Indian construction practices are lacking to apply use of base isolation in building design. It is suggested in the end that it must be motivated to study and research base isolation in Indian constrains and conditions.
\end{abstract}

\section{Introduction}

In mechanical engineering systems, to control the vibration, Tuned mass dampers are used. In order to minimize the vibrations of high storey building and engineering structures, Tuned Mass Dampers are widely adopted. Structural vibration control applications such as dynamic absorbers and Tuned Mass Dampers are of Tuned absorbers and Tuned dampers. The Linear uses and the rotary equivalent in rotational applications of inertial, resilient, and dissipative elements of the tools were mass, spring and dashpot. Accordingly, the tool of the application is sized. Vibration mitigation applications of pendulum absorbers/dampers and sloshing liquid absorbers/dampers configuration have been realized. To minimize the dynamic reaction to a structure, tuned mass dampers are attached. When the frequency is high, the damper vibrates with the building's motion. Usually the mass connected to the building through a spring-dashpot system and the friction energy by the dashpot will relatively develops the motion between the mass and the structure. As in increasing of damping ratio causes a reduction in the stress and acceleration. For buildings, it can be assumed $5 \%$ of damping. A TMD is a tool consisting of a mass, spring and a damper that is connected to a structure in order to min. the amplitude of unwanted motion. In case of earthquakes to control displacements, accelerations and internal stress can be done by tuned mass damper. The location on the structure where the Tuned Mass Dampers are attached is vital. There are different types of methods of control for large modern structures. This system is usually used to reduce vibration occurred by the wind and traffic like pedestrians/railway trains . Some vibrations may be acceptable for structures like slender bridges, stacks, high, and slender buildings has low levels of damping. Tuned mass dampers control the effect which is same as enlarge of damping. Without tuned mass dampers the figures achieve values of about $10 \%$ to $20 \%$ and the tuning frequency and the damping capability, the amplitude reduced based on the mass ratio. The mass, stiffness and damping ratio has chosen according different criteria. Here, a multistory building is assembled with a Tuned Mass System on the top of the roof.

\section{Need of Work}

Tremors on the earth's surface the triggered underground stress release along fault lines it is an earthquake. The earthquake force different types of dynamic loads. The biggest dynamic load is the inertia load created by the response of the concrete mass to ground accelerations. The behavior of structure depends on its energy absorption which is transmitted during an earthquake and its sustainability. The need for exploring various control devices which help in controlling the seismic response of buildings has come due to the damage and collapse of numerous concrete structures during recent earthquakes.

\section{Objective}

1. To study the seismic load carrying capacity that ascertained by using ETABS for framed structures

2. To analyze the several qualities like time 
periods, Amplitude, base shear in $\mathrm{x}$-axis and $\mathrm{y}$ axis.

3. To know the earthquake reaction of a ten storied building with reinforced cement concrete frame using ETABS in Zone IV with non linear time history analysis.

\section{Scope of the Study}

The scope of this project is as follows:

1. In the present study two different structures of each 10 stories (i.e. Rectangular and L-Shape in plan), of 3mts floor height located in Seismic Zone IV have been considered for this analysis. The plan and the design properties of the structures are shown below.
a. Self weight of the Structure - 25 $\mathrm{x} 10^{3} \mathrm{~N} / \mathrm{m}^{3}$
b. Live load $-3.5 \times 10^{3} \mathrm{~N} / \mathrm{m}$
c. Thickness of Outer wall $-230 \mathrm{~mm}$
d. Grade of Concre - M40
e. Grade of Reinforcement- Fe415

2. At the rooftop of the structure with a damping ratio of 5percentage using ETABS, steel dampers are used as Tuned Mass Damping Device on an R.C.C framed structure with Non Linear Dynamic Time History Analysis.

\section{Methodology}

With the help of ETABS package a framed building modeled with higher rise. Recorded critical locations of framed structure were analyzed with dynamic analysis, time period, magnitudes of displacements and then a TMD system has designed. TMD weights will be 3\% to $5 \%$ of the total structure weight. It was firstly examining individually and its natural frequency can be found. The structure was once again analyzed by keeping TMD on top of the building using dynamic analysis and the time period, displacement at the locations to illustrate the utility of the study, the comparison of the resultants are done without Tuned Mass Damper.

The methods of dynamic analysis are as follows:

1. Response spectrum analysis: A method which is relevant for the structures where modes, apart from fundamental one affect the reaction of multi-degree of freedom significantly. The reaction of multi-degree of freedom system show as the superposition of modal response, each modal reaction have been regulated from the spectral analysis of single degree of freedom systems, were combined to compute the total response. It is usually used in a response spectrum with conjunction.

2. Pushover analysis: It is a test to a structure which is a static non-linear analysis under permanent vertical loads and thereafter slowly increasing lateral loads. The equivalent static loads appropriately act for seismic induced forces. A plot of total base shear and roof displacement in a structure is acquired by the analysis for premature failure and weakness.
The test is carried up to failure, thus it shows measurement of collapse load and ductility capacity.

3. Inelastic time history analysis: During earthquake motion, an earthquake inadequate structure will be inelastic action. The inelastic time history analysis of the structure under strong motion earthquake brings out the regions of weakness and ductility demand in the building. It is an accurate method for assessing building performance.

\begin{tabular}{|c|c|c|}
\hline$\underline{1}$ & Structure type- & $\begin{array}{l}\text { Rigid frame Multi } \\
\text { storied (moment } \\
\text { resisting frame } \\
\text { for special } \mathrm{RC} \text { ). }\end{array}$ \\
\hline 2. & Earthquake Zone & $\begin{array}{l}\text { ( Table 2, IS } \\
1893-2002 \text { ) IV }\end{array}$ \\
\hline 3. & No. of Stories & 10 \\
\hline 4. & Floor height & 3 \\
\hline 5. & $\begin{array}{l}\text { Self weight of the } \\
\text { Structure }\end{array}$ & $25,000 \mathrm{~N} / \mathrm{m}^{3}$ \\
\hline 6. & Live load & $3,500 \mathrm{~N} / \mathrm{m}^{3}$ \\
\hline 7. & Slab depth & $0.15 \mathrm{~m}$ \\
\hline 8. & $\begin{array}{l}\text { Column } \\
\text { (size) }\end{array}$ & $0.6 \mathrm{mx} 0.6 \mathrm{~m}$ \\
\hline 9. & $\begin{array}{l}\text { Beam } \\
(\text { size })\end{array}$ & $0.45 \mathrm{mx} 0.4 \mathrm{~m}$ \\
\hline 10. & $\begin{array}{l}\text { Thickness of Outer } \\
\text { wall }\end{array}$ & $230 \mathrm{~mm}$ \\
\hline 11. & $\begin{array}{l}\text { Thickness of Inner } \\
\text { wall }\end{array}$ & $115 \mathrm{~mm}$ \\
\hline 12. & Grade of Concrete & M40 \\
\hline 13. & $\begin{array}{l}\text { Reinforcement } \\
\text { Grade }\end{array}$ & $\mathrm{Fe} 415$ \\
\hline 14. & RCC's specific & $25,000 \mathrm{~N} / \mathrm{m}^{3}$ \\
\hline
\end{tabular}




\begin{tabular}{|c|c|c|}
\hline & weight & \\
\hline 15. & $\begin{array}{l}\text { Brick's specific } \\
\text { weight }\end{array}$ & $20,000 \mathrm{~N} / \mathrm{m}^{3}$ \\
\hline 16. & Imposed load & $4 \mathrm{KN} / \mathrm{m}^{3}$ \\
\hline 17. & Type of soil & Rock \\
\hline 18. & Time History. & $\begin{array}{l}\text { As per I.S } 1893 \\
\text { (part 1): } 2002 .\end{array}$ \\
\hline 19. & Young's Modulus & $\begin{array}{l}5000 V_{\mathrm{fck}} \\
=5000 V_{40} \\
=31622.6\end{array}$ \\
\hline 20. & $\begin{array}{l}\text { Moment of Inertia } \\
\text { of column }\end{array}$ & $0.0108 \mathrm{~m}^{4}$ \\
\hline 21. & $\begin{array}{l}\text { Each column } \\
\text { stiffness }\end{array}$ & $\begin{array}{l}12 \mathrm{EI} / 13= \\
\frac{12 \times 31622.6 \mathrm{x}}{10^{\wedge} 3 \times 0.0108} \\
= \\
151788.48 \mathrm{Kn} / \mathrm{m}\end{array}$ \\
\hline 22. & $\begin{array}{l}\text { Total stiffness of } \\
\text { column }\end{array}$ & $\begin{array}{l}\text { total of each } \\
\text { stiffness column } \\
\text { x No. of columns } \\
\quad 72 \times \\
151788.48= \\
10928770.56\end{array}$ \\
\hline 23. & Weight of dampers & $521 \mathrm{KN}$ \\
\hline 24. & Mass of dampers & $527 \mathrm{KN}$ \\
\hline 25. & Stiffness of damper & $570 \mathrm{KN} / \mathrm{m}$ \\
\hline 26. & Damping & $123 . \mathrm{S} / \mathrm{m}$ \\
\hline
\end{tabular}

26. Calculation of weight at each floor:

(a) Slab weight: Slab thickness in $\mathrm{m} x$ slab area $\mathrm{x}$ unit weight of concrete $=[42 \times 48] \times 0.15 \times 25=7560 \mathrm{KN}$

(b) Beam weight : $\mathrm{C} / \mathrm{s}$ are of beam $\mathrm{x}$ total Length $\mathrm{x}$ unit weight of concrete

$$
\begin{aligned}
& =[(42 \times 8)+(48 \times 9)] \times 0.45 \times 0.4 \times 25 \\
& =3456 \mathrm{KN}
\end{aligned}
$$

(c) Column weight: $\mathrm{C} / \mathrm{s}$ are of column $\mathrm{x}$ height no. of columns $\times$ concrete unit weight $=0.6$ x $0.6 \times 3 \times 72 \times 25$ $=1944 \mathrm{KN}$

(d) Weight of outer walls: [ $(42 \times 2)+(48 \times 2)]$ x 0.23 x 3.0 x $20=2484 \mathrm{KN}$

(e) Inner walls weight: $=[(42 \times 6)+(48 \times 7)$ ] $\times 0.115 \times 3.0 \times 20=4057 \mathrm{KN}$

(f) Imposed load: $42 \times 48 \times 4=8064 \mathrm{KN}$

Total weight at each floor $=$

(beam+innerwalls + slab + columns + outerwalls + imposed load) weights $=27565 \mathrm{KN}$

\section{Rectangular plan:}

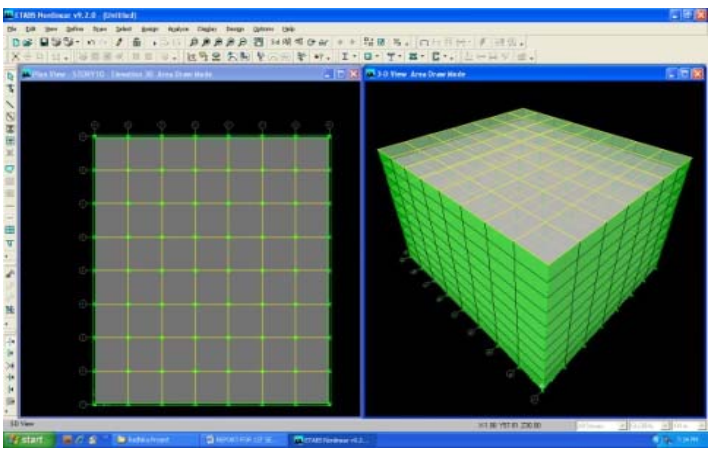

Figure:1 Symmetrical building Plan without TMD

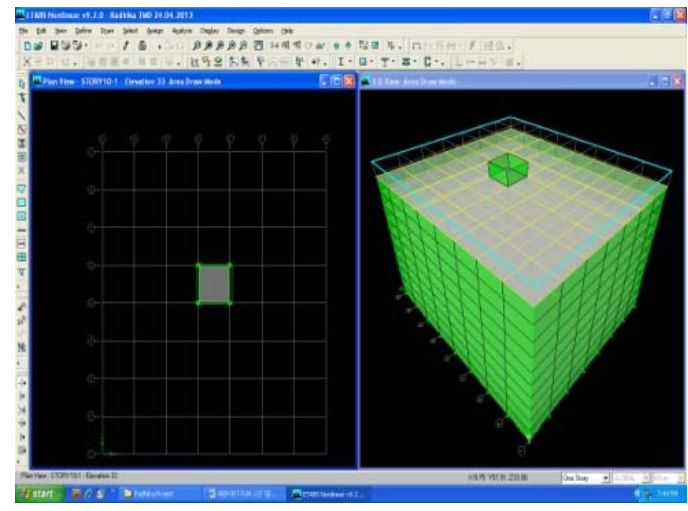

Figure:2 Symmetrical building plan (with TMD).

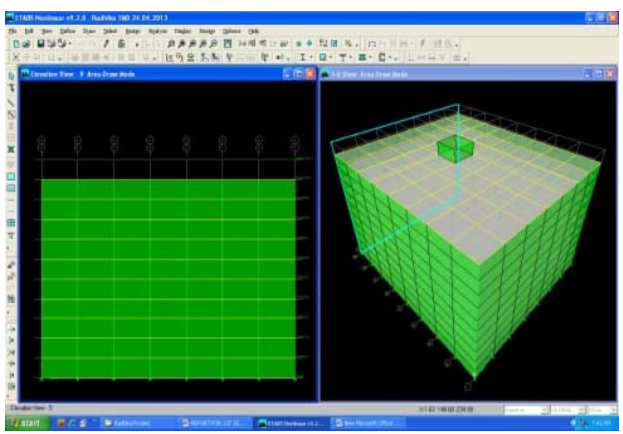

Figure : 3 symmetrical building elevation. 


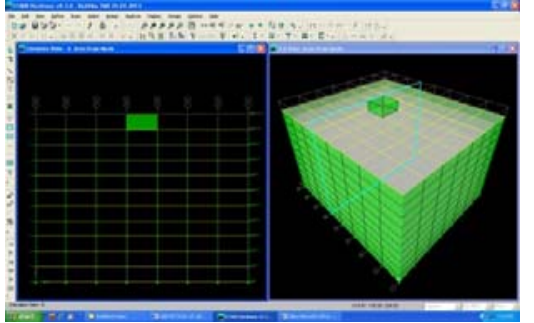

Figure : 4 symmetrical building elevation

\section{Results}

Non linear Dynamic Time History Cases studied 10 storied R.C.C. framed structure by applying TMD with damping ratio of 5 percentage in ETABS at top of building. In the present study two R.C framed models with ten stories i.e., rectangular in plan and the other is having L-shape in plan. At the centre of the grid the tuned mass damper was placed in plan.

i)Rectangular Plan Building: Placing of Damper in Columns at top of the Building

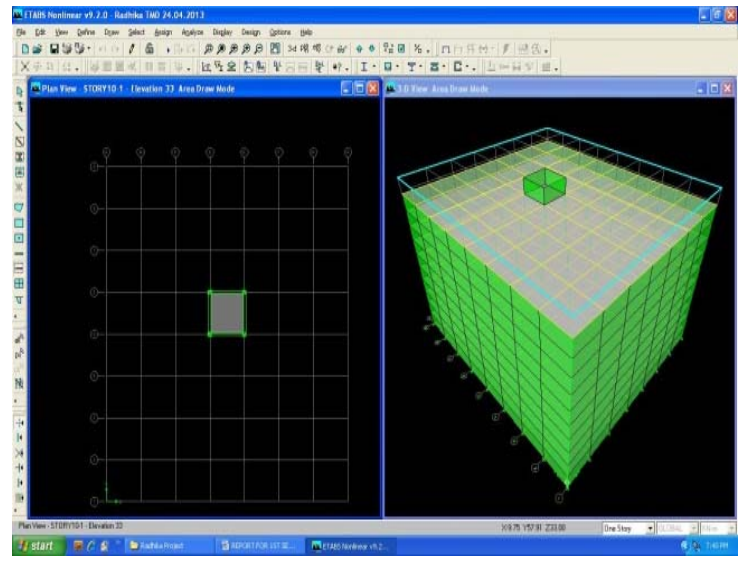

Figure: 7 Plan showing the TMD placed at top floor for symmetrical section.

Case I: Without TMD \& With TMD: Time Period Vs Base shear x:

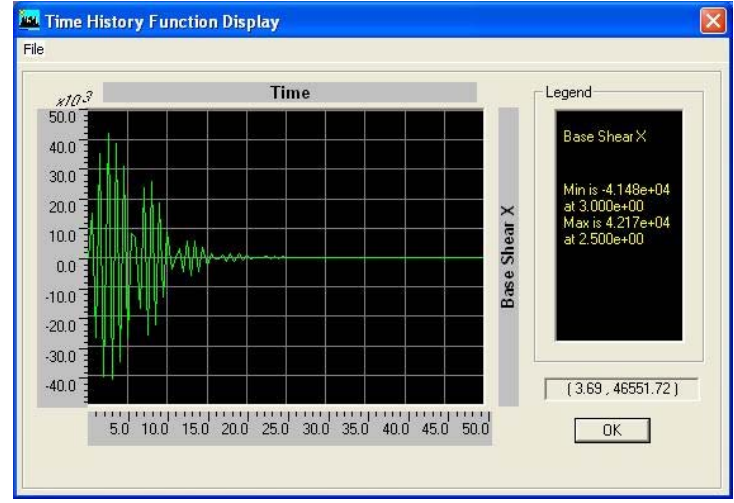

Figure: 8 Time Vs Base shear X Without the TMD graph

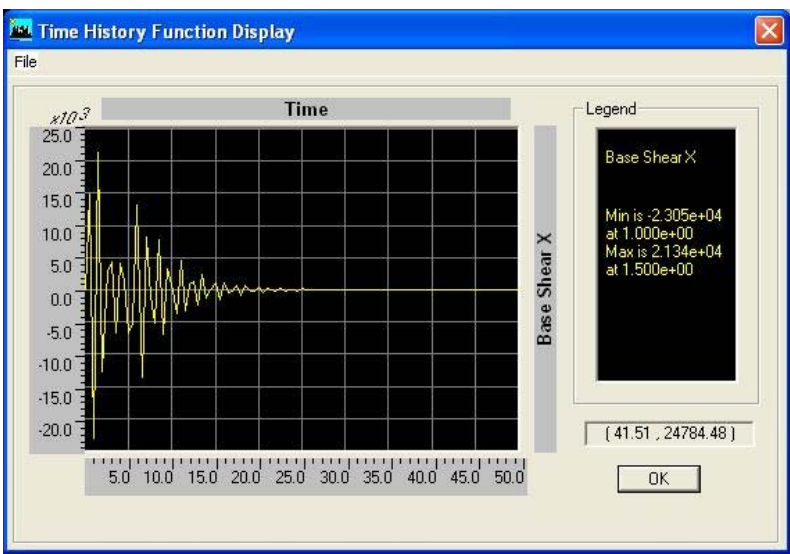

Figure: 9 Time Vs Base shear X With the TMD graph

Case II: Without TMD \& With TMD: Time Period Vs Base Shear y:

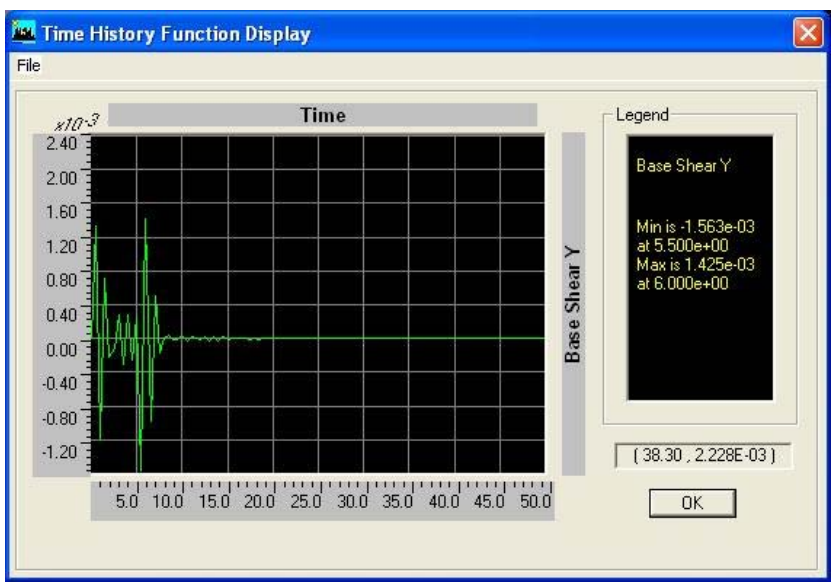

Figure: 10 Time Vs Base shear y Without the TMD graph 


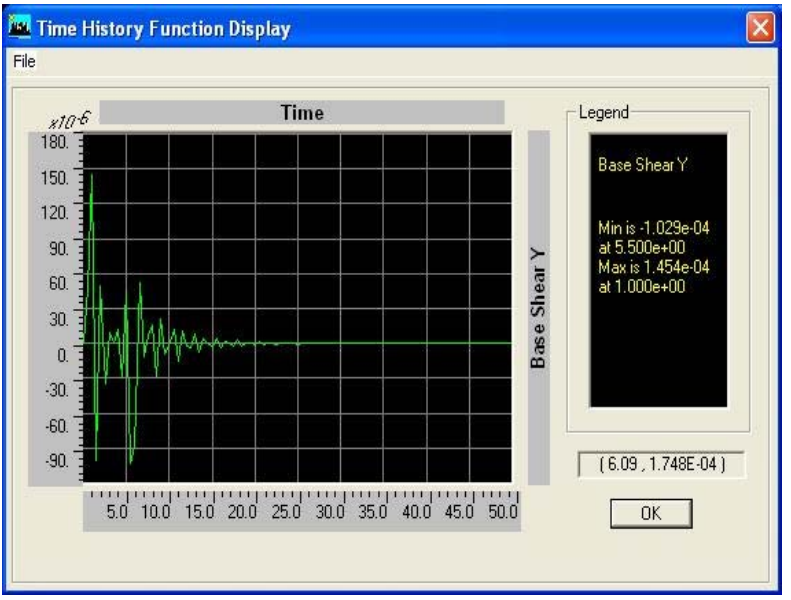

Figure : 11 Time Vs Base shear y With TMD graph

\section{CASE III: Storey Number Vs Max Displacement:}

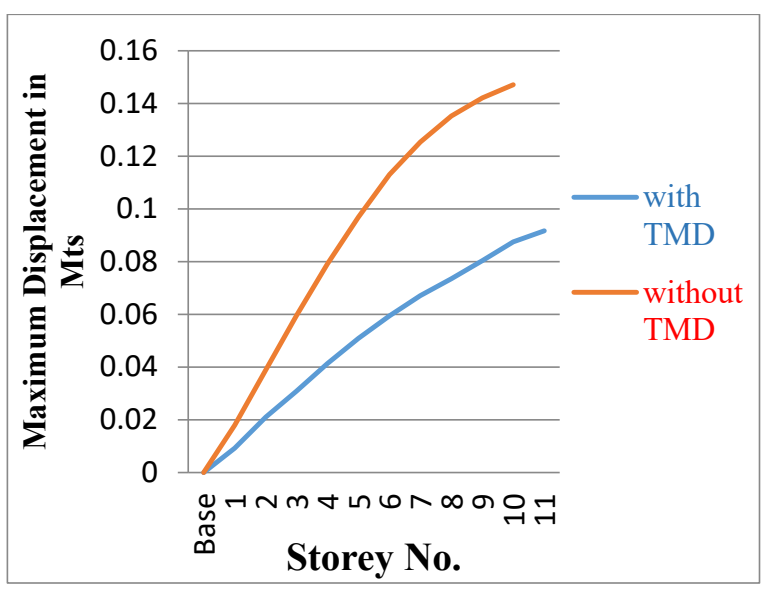

Figure: 12 Storey number Vs Maximum Displacement graph

\section{G. DISCUSSIONS}

Based on the limited studies carried out it is observed that:

1) The steel damper provided to be an effective TMD mechanism in columns at top of the building.

2) Significant contribution from the TMD was noticed when the supports of the columns corresponding to the TMD were hinged.

3) The study was done on the mass of TMD approximately $4 \%$ - $5 \%$ mass of structure.

4) The sizing of the structural elements of the TMD was made so the frequency of the TMD approximately matches the frequency of the structure.

5) From the study, it is observed that a suitable TMD can be designed for a particular building using ETABS package.

\section{Conclusions}

As per IS: 1893:2002 (part-1) with 5percentage of structural damping, based on the outputs from the ETABS package following conclusions are made.

1. The frequency of Tuned Mass Dampers appears same to the fundamental mode of the structure with $5 \%$ mass of TMD.

2. Using Tuned Mass Dampers in the form of steel dampers, the amplitude of vibration decreased by $51 \%$ for Symmetrical Buildings.

3. Similarly for symmetrical Buildings, base shear value decreases to $56 \%$ as using steel dampers.

\section{Future Scope}

1. Further studies have to be carried out for different TMD's i.e. Active, Semi active, etc.

2. With experimental studies the effect of TMD needs to be validated.

3. Further studies have to be carried out for finding the Stiffness Matrix and Mass Matrix of an element.

\section{References}

1. Allen J. Clark. "Multiple Passive Mass tuned mass damper for reducing earthquake Induced Building motion".

2. Jo, Byung-Wan, Ghi-Ho Tae, and Du-Wha Lee. International journal of pressure vessels and piping 78.10, 667-675(2001)

3. Chen Wai-fah. "Structural Engineering Hand book". CRC Press LLC, (1999)

4. Chi-Chang Lin, Jin-Min Ueng, Teng-Ching Huang, Engineering structures 22, 513-524 (1999)

5. Chouw, Nawawi, Thirteenth World Conference on Earthquake Engineering, Vancouver, BC, Canada, (2004)

6. Den Hortog's, Undamped dynamic vibration absorber- Mechanical Vibrations, (1928)

7. Sadek, Fahim, et al," Earthquake Engineering \& Structural Dynamics 26.6, 617-635 (1997)

8. G. W,Housner, Structural control: past, present, and futurell Journal of Engineering Mechanics, 123.9,15617(1996)

9. Webster, Anthony C., and Rimas Vaicaitis. , Engineering Journal of the American Institute of Steel Construction 29.3, 116-124(1992)

10. Symans, Michael D., and Michael C. Constantinou. Engineering structures 21.6, 469487 (1999) 
11. Kwok, K. C. S., and B. Samali, Engineering structures 17.9, 655-667 (1995)

12. Wong, Kevin KF, and Rong Yang, Journal of Engineering Mechanics 125.10, 1190-1199 (1999)

13. Lee Chien-Liang, ChenYung-Tsang, Engineering Structures 28, 43-53, (2006).

14. Mario Paz. "Structural Dynamics Theory and computation".

15. Setareh, Mehdi, and Robert D. Hanson, Journal of Structural Engineering 118.3, 741-762(1992)

16. Agrawal, Pankaj, and Manish Shrikhande, PHI Learning Pvt. Ltd., (2006)

17. Nawrotzki, Peter, Seventh International Congress on Advances in Civil Engineering. Istanbul, Turkey: Yildiz Technical University, (2006)

18. Yang, Runlin, Xiyuan Zhou, and Xihui Liu, Earthquake engineering and engineering vibration 1.1 ,111-118 (2002)

19. Saidi, Ibrahim, et al., Australian Earthquake Engineering Society Conference (2007)

20. Singh, M. P., and L. M. Moreschi, (2000)

21. S.K Duggal. - "Earthquake Resistance Design of Structures"

22. Chen, Genda, Jingning $\mathrm{Wu}$, and Menglin Lou, 66 (1999)

23. Lin, Y.C., Wu, F., Wang, Q.-W., Chen, D.-D., Singh, S.K, ) Vacuum, 151, pp. 283-293, (2018)

24. Kora, P., Kalva, S.R, SpringerPlus, 4 (1), art. no. 481, 19 (2015)

25. Sateesh, N., Sampath Rao, P., Ravishanker, D.V., Satyanarayana, K, Materials Today: Proceedings, 2 (4-5), pp. 2902-2908(2015).

26. Hussaini, S.M., Krishna, G., Gupta, A.K., Singh, S.K, Journal of Manufacturing Processes, 18, pp. 151-158 (2015)

27. Raghunadha Reddy, T., Vishnu Vardhan, B., Vijayapal Reddy.P, International Journal of Applied Engineering Research, 11 (5), pp. 3092-3102(2016) 